\title{
Hyperbaric oxygen in chronic progressive multiple sclerosis: visual evoked potentials and clinical effects
}

\author{
JACK NEIMAN, ${ }^{*}$ BENGT Y NILSSON, $†$ PER O BARR, $¥$ DAVID JD PERRINS $\ddagger$ \\ From the Departments of Neurology and Clinical Neurophysiology, ${ }^{*} \dagger$ Söder Hospital and the Department of \\ Hyperbaric Oxygenation, Rosenlund Hospital, $\ddagger$ Stcckholm, Sweden
}

SUMMARY The effects of hyperbaric oxygen at a pressure of two atmospheres absolute were studied in a group of patients with chronic progressive multiple sclerosis. A slight but statistically insignificant shortening of the visual evoked potential latencies was seen after treatment with hyperbaric oxygen as compared with placebo treatment. The treatment did not appreciably halt the progression of the disease and deterioration occurred more often among the patients in the treatment group than in the control group.

The absence of an effective treatment for multiple sclerosis has led to investigation of hyperbaric oxygen as a possible means of modifying features of the disease. In 1970, Broschetty and Černoch' reported an improvement in patients with multiple sclerosis after treatment with hyperbaric oxygen. Since then the problem has been studied by several investigators. ${ }^{2-5}$ All have reported some improvement ranging from minimal to dramatic. In 1983 Fischer et al ${ }^{6}$ reported transient improvement among patients with multiple sclerosis treated with hyperbaric oxygen at a pressure of 2 atmospheres absolute for 90 minutes at a time during 20 exposures in a placebo-controlled double-blind randomised study. Furthermore, Procop et al ${ }^{7}$ and Warren et al $^{\mathbf{s}}$ demonstrated in rodents that experimental allergic encephalomyelitis, an animal model for demyelinating disease, could be modified by hyperbaric oxygenation.

Evoked potentials are, in general, considered to be a good measure of conduction along myelinated fibre tracts and seem to follow the course of multiple sclerosis." To determine whether the latencies of visual evoked potentials (VEPs) change after treatment with hyperbaric oxygen and evaluate its clinical effect, a double-blind, placebo-controlled study was initiated.

Address for reprint requests: Jack Neiman, MD, Department for Clinical Alcohol and Drug Research, Karolinska Hospital, S-104 01 Stockholm, Sweden.

Received 5 September 1984.

Accepted 29 October 1984

\section{Patients and methods}

\section{Patients}

Twenty-four patients volunteered for the study after having its nature, purpose and risks explained to them. After the first compression four patients withdrew, one because of ear discomfort, and three because of claustrophobia. One patient could not continue the treatment because of alcoholism; he received only two treatments and was dropped from the follow-up. Thus, nineteen patients were included in the trial.

Age, sex, duration of the disease, Kurtzke's Disability Status Scale score and Functional System Scale score (the sum of the seven functional system scores) ${ }^{10}$ before treatment are given in table 1 . All patients had been diagnosed by a neurologist and observed afterwards for many years at the section of Neurological Rehabilitation of the Department of Neurology. All had had at least two well documented attacks involving different parts of the CNS. The attacks were separated by a period of at least one month and each attack had lasted at least 24 hours. All patients fulfilled the criteria for clinically definite multiple sclerosis group $A_{1}\left(C_{\left.1 M S A_{1}\right)}\right.$ as proposed by Poser et al. ${ }^{\prime 1}$ All patients also had evidence of pathological VEPs before treatment. Furthermore, in most cases the patient's history included evidence of increased intrathecal production of immunoglobulin $\mathrm{G}$ ( IgG), different from that found in the same patient's serum. This, together with the CSF oligoclonal IgG response, found in the patient's CSF, represents the most constant and characteristic aspect of the CSF profile of multiple sclerosis. ${ }^{1213}$

Eleven patients were ambulatory and eight required the use of a wheelchair. The majority of patients had had a relapsing-remitting course in the beginning of the disease. All participants were, however, considered to have chronic progressive type of multiple sclerosis before entry to the study.

The patients were assigned to the treatment (10 
Table 1 Age and sex distribution and clinical features in patients treated with hyperbaric oxygen $(\mathrm{HBO})$ and controls

\begin{tabular}{llr}
\hline & $H B O$ & Placebo \\
\hline Sex (Male/female) & \multicolumn{1}{c}{$5 / 5$} & \multicolumn{1}{c}{$2 / 7$} \\
Age (yr) & $37.8 \pm 1 \cdot 8^{*}$ & $38 \cdot 3 \pm 2 \cdot 1$ \\
Duration of disease (yr) & $11 \cdot 5 \pm 1.6$ & $12 \cdot 4 \pm 1 \cdot 7$ \\
Disability score (DSS) & $6 \cdot 1 \pm 0.2$ & $6 \cdot 0 \pm 0.3$ \\
Functional score (FSS) & $9 \cdot 5 \pm 1.5$ & $10.6 \pm 1.4$ \\
\hline
\end{tabular}

*The figures represent mean \pm SEM

patients) and control group (9 patients) with the aid of a table of random numbers. No changes were made in their customary habits, physical therapy or medication during the trial. None of the patients received immunosuppressive therapy during the treatment or the preceding 3 month period.

Clinical assessment was based on the numerical grading, ranging from zero (normal) to 10 (dead) on Kurzke's Disability Status Scale and Functional System Scale, the latter providing the numerical grading of pyramidal, cerebellar, brainstem, sensory, bowel-bladder, visual and mental functions. The assessment was performed by the same neurologist, unaware of the treatment being given, approximately one week before and one week after treatment.

\section{Visual Evoked Potentials}

VEPs were recorded between a midoccipital electrode $50 \mathrm{~mm}$ above the inion and a midfrontal electrode. EEG activity was analysed with a TOENNIES DA II $R$ equipment (amplitude band pass $0 \cdot 5-3000 \mathrm{~Hz}$ ). Pattern reversal stimulation was obtained by backprojecting a black-andwhite checkerboard pattern which was displaced sideways at $700 \mathrm{~ms}$ intervals by a stepwise rotatable mirror (Digitimer stimulator D110). ${ }^{14}$ Stimulus field subtended $8.8^{\circ}$ with $23^{\prime \prime}$ checks at $98 \%$ contrast. ${ }^{15}$ An average of 64 or 128 responses were obtained at least twice to get reproducible wave forms. The upper limit of normal latency of $P$ 100 (the dominant positive wave) is $109 \mathrm{~ms}$ in our laboratory (mean $+3 \mathrm{SD}$ ). Recordings were made during the week preceding the first treatment and repeated within one week after the last treatment.

The differences in latencies in the treatment and control groups were compared statistically with the aid of analysis of variance (from statistical package ANOVA) with the following factors: groups (treatment and control), eyes (right and left) and patients within the groups.

\section{Treatment}

Monoplace chambers (VICKERS models CHS and HBS) were used. The treatment group received $100 \%$ oxygen at a pressure of 2 atmospheres absolute for 90 minutes. The control group received air at slightly elevated pressure (1.2 atmospheres absolute) for five minutes, after which the pressure was gradually decreased to normal. The duration of these exposures was also 90 minutes. Both groups received 20 exposures. During the treatment and followup the code of randomisation was known only to the chamber operators. The code was broken after the assessment was completed and the results summarised and reported.
Table 2 Clinical outcome, assessed within one week and six months after treatment with $\mathrm{HBO}$ and placebo

\begin{tabular}{|c|c|c|c|c|}
\hline & \multicolumn{2}{|l|}{$H B O$} & \multicolumn{2}{|l|}{ Placebo } \\
\hline & I week & 6 months & 1 week & 6 months \\
\hline Improved ${ }^{*}$ & $3 / 10$ & $1 / 10$ & $5 / 9$ & $3 / 9$ \\
\hline Deteriorated* & $3 / 10$ & $5 / 10$ & $0 / 9$ & $2 / 9$ \\
\hline Unchanged & $4 / 10$ & $4 / 10$ & $4 / 9$ & $4 / 9$ \\
\hline
\end{tabular}

* Deterioration or improvement was defined arbitrarily as an increase or decrease, respectively, of at least one point on the FSS when compared to the assessment before treatment.

The study protocol was approved by the local ethical committee.

\section{Results}

\section{Clinical response}

The results of clinical assessment, based on the Functional System Scale, are summarised in table 2. The changes in central nervous system functions, registered within one week after treatment, were usually slight. All but one of the patients moved only one step on the Functional System Scale. None improved or deteriorated to the extent that this could be registered on the Disability Status Scale.

Improvement in bladder function was reported by two patients in the hyperbaric oxygen and by three patients in the control group. Improvement in brain stem function was noticed in one patient in the placebo group. Two patients improved in sensory

Table $3 P \overline{100}$ latencies in $\mathrm{ms}$ with right and left eye stimulation before treatment with $\mathrm{HBO}$ and placebo, and changes in latencies recorded within one week after treatment

\begin{tabular}{|c|c|c|c|c|c|}
\hline \multicolumn{3}{|l|}{$H B O$} & \multicolumn{3}{|l|}{ Placebo } \\
\hline Patient & $\begin{array}{l}\text { Before } \\
\text { treatment }\end{array}$ & Change & Patient & $\begin{array}{l}\text { Before } \\
\text { treatment }\end{array}$ & Change \\
\hline 1 & $\begin{array}{l}101 \\
123\end{array}$ & $\begin{array}{l}-2 \\
+3\end{array}$ & 1 & $\begin{array}{l}228 \\
175\end{array}$ & $\begin{array}{l}+6 \\
+3\end{array}$ \\
\hline 2 & $\begin{array}{l}170 \\
165\end{array}$ & $\begin{array}{l}-5 \\
-3\end{array}$ & 2 & $\begin{array}{l}175 \\
182\end{array}$ & $\begin{array}{l}0 \\
0\end{array}$ \\
\hline 3 & $\begin{array}{l}145 \\
116\end{array}$ & $\begin{array}{l}0 \\
0\end{array}$ & 3 & $\begin{array}{l}138 \\
134\end{array}$ & $\begin{array}{r}0 \\
-1\end{array}$ \\
\hline 4 & $\begin{array}{l}175 \\
160\end{array}$ & $\begin{array}{r}0 \\
-5\end{array}$ & 4 & $\begin{array}{l}165 \\
215\end{array}$ & $\begin{array}{r}+5 \\
+15\end{array}$ \\
\hline 5 & $\begin{array}{l}116 \\
116\end{array}$ & $\begin{array}{l}-2 \\
-4\end{array}$ & 5 & $\begin{array}{l}212 \\
225\end{array}$ & $\begin{array}{l}0 \\
0\end{array}$ \\
\hline 6 & $\begin{array}{l}\text { NR* } \\
\text { NR }\end{array}$ & $\begin{array}{l}\text { NR } \\
\text { NR }\end{array}$ & 6 & $\begin{array}{l}175 \\
130\end{array}$ & $\begin{array}{l}+5 \\
-5\end{array}$ \\
\hline 7 & $\begin{array}{l}178 \\
175\end{array}$ & $\begin{array}{l}-1 \\
-5\end{array}$ & 7 & $\begin{array}{l}114 \\
116\end{array}$ & $\begin{array}{l}0 \\
0\end{array}$ \\
\hline 8 & $\begin{array}{l}137 \\
117\end{array}$ & $\begin{array}{l}+3 \\
-2\end{array}$ & 8 & $\begin{array}{l}160 \\
202\end{array}$ & $\begin{array}{l}-6 \\
-3\end{array}$ \\
\hline 9 & NR & $\begin{array}{l}\text { NR } \\
\text { NR }\end{array}$ & 9 & $\begin{array}{l}225 \\
150\end{array}$ & $\begin{array}{r}+10 \\
+3\end{array}$ \\
\hline 10 & $\begin{array}{l}120 \\
113\end{array}$ & $\begin{array}{l}0 \\
0\end{array}$ & & & \\
\hline $\begin{array}{l}\text { Mean } \\
\text { SEM }\end{array}$ & $\begin{array}{r}139.1 \\
\quad \pm 6.9\end{array}$ & $-1 \cdot 5$ & & $\begin{array}{l}175 \cdot 2 \\
\pm 9 \cdot 7\end{array}$ & $+1 \cdot 8$ \\
\hline
\end{tabular}

*Not recordable 
function, one in the treatment and one in the control group.

Two patients in the hyperbaric oxygen group deteriorated in sensory function. One patient deteriorated in two functional systems - sensory and pyramidal. He also belonged to the treatment group. The cerebellar, visual, mental and bowel functions remained unchanged, both in the hyperbaric oxygen and control groups.

All participants in the study were again clinically assessed 6 months after treatment. By this time, clinical signs indicating progression of the disease as compared to previous assessment, had appeared in four more patients. The deterioration, which was noticed in sensory, pyramidal and cerebellar systems, was again slight, not influencing the Functional System Scale more than one point. Two out of these four patients had been treated with hyperbaric oxygen. Side effects during hyperbaric oxygen treatment were noticed in only one patient who reported transient ear discomfort.

\section{Visual evoked potentials}

$P \overline{100}$ latencies before, and changes recorded within one week after treatment, are given in table 3. VEPs recorded before treatment showed a slight prolongation in latency $(110-125 \mathrm{~ms})$ in one or both eyes in seven patients. A delay of more than $15 \mathrm{~ms}$ above the normal limit was recorded in both eyes in 10 patients. Responses could not be evoked in two patients. Only one out of all investigated eyes in 19 patients gave a normal $P \overline{100}$ wave. The average latency in the treatment group was shorter than in the control group.

The individual changes in latencies after treatment were small. Using the criterion adopted by Matthews and Small, ${ }^{16}$ defining $10 \mathrm{~ms}$ as the minimum value for changes of latency to be taken into account, none of the patients in the treatment group and only two patients in control group showed appreciable prolongation in VEP latencies. However, these changes were not correlated to clinical deterioration. After treatment the average VEP latency for the hyperbaric oxygen group was slightly shortened $(-1.5 \mathrm{~ms})$, whereas the control group showed an opposite tendency $(+1.8 \mathrm{~ms})$. The difference between the groups was not statistically significant (analysis of variance, $p>0 \cdot 05$ ). The changes in $P \overline{100}$ amplitudes were very small in absolute values $(0 \cdot 5-6 \cdot 0 \mu \mathrm{V})$ and are not reported in this paper.

\section{Discussion}

All participants in this study had a well-established diagnosis of multiple sclerosis. The treatment and control groups were well matched with respect to age, duration of the disease, Disability Status Scale and Functional System Scale. After withdrawal of some patients and randomisation, the sex distribution and the average VEP latencies were somewhat uneven when comparing the treatment and control groups.

An association between the prolongation of latencies of evoked potentials and clinical progression has been suspected. ${ }^{917}$ However, the method is not considered to be very sensitive in detecting clinical remissions. ${ }^{16}$ Little is yet known as to how the treatment with hyperbaric oxygen influences the evoked potentials. An improvement of evoked potentials during the treatment in one patient has been reported by Hammond et al. ${ }^{18}$

In our study the VEP recordings of all the patients demonstrated a delayed conduction in all but one eye before the treatment, reflecting the massive involvement of visual pathways by the disease. Furthermore, responses with ill-defined peaks made the exact determination of $P \overline{100}$ difficult in many cases. The changes in the VEP latencies were slight and the differences between the groups negligible, suggesting a lack of effect of hyperbaric oxygen on the conduction along the visual pathways in this patient group.

The aetiology and pathogenesis of multiple sclerosis is still poorly understood. How hyperbaric oxygen could possibly influence the disease is discussed elsewhere. ${ }^{619}$ The clinical improvement reported by previous investigators ${ }^{1-6}$ was not found in this trial. However, the majority of the previous studies were performed in multiplace chambers compressed with air and oxygen given to the patients by face mask. Due to leakage therefore, $100 \%$ oxygen was not delivered, as shown by arterial oxygen measurements. $^{6}$ In this study single place chambers, where patients are treated in an atmosphere of compressed pure oxygen, were used and this difficulty was eliminated. Therefore the results of this study do not necessarily imply that more successful treatment at lower pressures is ruled out. The difficulties of establishing the effect of treatment in multiple sclerosis are well-known. ${ }^{2021}$ The results of this study suggest that treatment with hyperbaric oxygen did not improve the clinical status in chronic progressive multiple sclerosis or stop the progression of the disease. However, our patient series were small and further studies, particularly with less affected patient groups and with variable pressure regimens, are needed to elucidate the role of hyperbaric oxygen in the treatment of multiple sclerosis.

We express our thanks to Associate Professors Karl 
Ekbom and Matti Hillbom for helpful comments during the preparation of this manuscript.

\section{References}

' Broschetty V, Černoch J. Aplikace Kyslíku za pretlaku u některých neurologickych onemocněni. Bratisl Lek Listy 1970;53:298-302.

${ }^{2}$ Neubauer RA. Exposure of multiple sclerosis patients to hyperbaric oxygen at 1.5-2 ATA: a preliminary report. J Fla Med Assoc 1980;67:498-504.

${ }^{3}$ Pallotta R. La terapia iperbarica della sclerosi multipla. Minerva Med 1982;73:2947-54.

${ }^{4}$ Golovkin VI, Zaitsev VS, Lotovin AP. Giperbaricheskaia oksigenatsiia kak immunostimuliator pri rasseiannom skleroze. Sov Med 1982;12:70-5.

${ }^{5}$ Davidson DLW. Hyperbaric oxygen therapy in the treatment of multiple sclerosis. London: ARMS Educational Services 1983.

' Fischer BH, Marks M, Reith T. Hyperbaric-oxygen treatment of multiple sclerosis. A randomized, placebo-controlled, double-blind study. $N$ Engl J Med 1983;308:181-3.

${ }^{7}$ Procop LD, Grasso RJ. Ameliorating effects of hyperbaric oxygenation on experimental allergic encephalomyelitis. Brain Res Bull 1978;3:221-5.

${ }^{8}$ Warren J, Sacksteder MR, Thuning CA. Oxygen immunosuppression: modification of experimental allergic encephalomyelitis in rodents. J Immunol 1978;121:315-20.

' Walsh JC. Garrick R, Cameron J, McLeod JG. Evoked potential changes in clinically definite multiple sclerosis: a two year follow up study. J Neurol Psychiatry 1982;45:494-500.

${ }^{10}$ Kurtzke JF. Further notes on disability evaluation in multiple sclerosis with scale modifications. Neurology (Minneap) 1965;15:654-61.
"Poser CM, Paty DW, Scheinberg L, et al. New diagnostic criteria for multiple sclerosis: Guidelines for research protocols. Ann Neurol 1983;13:227-31.

${ }^{12}$ Link $\mathrm{H}$. Immunoglobulin $\mathrm{G}$ and low molecular weight proteins in human cerebrospinal fluid: Chemical and immunological characterisation with special reference to multiple sclerosis. Acta Neurol Scand 1967;43 (suppl 8): 1-136.

${ }^{13}$ Walsh MJ, Tourtellotte WW, Potvin AR, Potvin JH. The cerebrospinal fluid in multiple sclerosis. In: Hallpike JF, Adams CWM, Tourtellotte WW, eds. Multiple Sclerosis. Pathology, Diagnosis and Management. London: Chapman and Hall, 1973:661-4.

${ }^{14}$ Halliday AM, McDonald WI, Mushin J. Visual evoked responses in diagnosis of multiple sclerosis. $\mathrm{Br} \mathrm{Med} \mathrm{J}$ 1973;4:661-4.

${ }^{15}$ Nilsson, BY. Visual evoked responses in multiple sclerosis: comparison of two methods for pattern reversal. J Neurol Neurosurg Psychiatry 1978; 41:499-504.

${ }^{16}$ Matthews WB, Small DG. Serial recording of visual and somatosensory evoked potentials in multiple sclerosis. J Neurol Sci 1979;40:11-21.

${ }^{17}$ de Weerd JC, Jonkman EJ. Changes in visual and short latency somatosensory evoked potentials in patients with multiple sclerosis. Adv Neurol 1982;32:527-34.

${ }^{18}$ Hammond EJ, Ibarra EL. Evoked potentials after hyperbaric oxygen treatment of multiple sclerosis. $N$ Engl Med 1983;309:241-2.

${ }^{19}$ Mertin J, McDonald WI. Hyperbaric oxygen for patients with multiple sclerosis. Br Med J 1984;288:957-60.

${ }^{20}$ Schumacher GA. Critique of experimental trials of therapy in multiple sclerosis. Neurology (Minneap) 1974;24: 1010-4.

${ }^{22}$ Brown JR. Problems in evaluating new treatments for multiple sclerosis. Neurology (Minneap) 1980;30: 8-11. 